\title{
LOS LIBROS ESPAÑOLES DEL COMERCIANTE ESCOCÉS DAVID STEUART
}

\author{
GABRIEL SÁNCHEZ ESPINOSA \\ Queen's University Belfast
}

\begin{abstract}
La década de los veinte del siglo XIX fueron los años dorados de las subastas de libros españoles en Inglaterra. La intervención británica en la península durante la Guerra de la Independencia, las traducciones y estudios literarios de Robert Southey y Lord Holland, la presencia en Inglaterra de los liberales españoles exiliados y la lucha por la independencia de la América española, habían despertado un gran interés por la cultura, la lengua y la literatura españolas. En la estela de la locura bibliómana en Inglaterra -que tiene su hito en la venta Roxburghe del año 1812-, la demanda de libros españoles antiguos y raros crece hasta niveles antes nunca vistos. Por otro lado, la inestabilidad militar, política y económica de España favorece la exportación de valiosas colecciones de libros. Entre otras, se venden en esos años, al completo o en parte, en las salas de subastas londinenses, campo de batalla de los bibliómanos, las bibliotecas de José Antonio Conde, Juan de Iriarte y Gregorio Mayans, mientras que libreros especializados en libros raros como Thomas Thorpe se encargan de la venta de colecciones como la del marqués de Astorga. El mismo Vicente Salvá, que había sido diputado a Cortes por Valencia en 1822, abre en 1825 su Librería Clásica y Española en el 124 de Regent Street, procediendo parte de sus fondos de la antigua biblioteca de Mayans ${ }^{1}$. Frente al

1 Para todo lo referente al interés por los libros españoles en Inglaterra en el contexto de la bibliomanía, véase el artículo de N. GLENDINNING, «Spanish Books in England: 1800-1850», Transactions of The Cambridge Bibliographical Society 3 (1959), pp. 70-92. Véanse también G. DE ANDRÉs, «El hispanista Obadiah Rich y la almoneda de libros españoles en Londres en 1824», Boletín de la Real Academia de la Historia 190 (1993), pp. 283-311 y L. DE USOZ, «Mss. españoles vendidos en Londres en 1836 en la almoneda que se hizo de la librería de Mr. Heber que los recogió», Revista de Archivos, Bibliotecas y Museos 14 (1906), pp. 378-385. Por lo que respecta a las actividades políticas y culturales de los los exiliados españoles en Inglaterra, ha de consultarse el estudio ya clásico de V. LLORENS, Liberales y románticos. Una emigración española en Inglaterra (1823-1843), Madrid, Castalia, 1962.
\end{abstract}


dinamismo con que se oferta y se solicita el libro antiguo español en el mercado londinense de los años 1820-1830, el siglo XVIII nos ofrece un marcado contraste: pocos bibliófilos británicos tienen libros españoles en sus bibliotecas - la Bibliomania de Dibdin ${ }^{2}$ refiere sólo los casos de Anthony Collins (vendida en 1730), del conde de Oxford (vendida en 1744), de Martin Folkes (vendida en 1756) y del general Dormer (subastada en 1764), a los que habría que añadir los eruditos Thomas Crofts ${ }^{3}$ (subastada en 1783) y John Bowle ${ }^{4}$ (subastada en 1790)—, consecuencia, en opinión de Nigel Glendinning, más de la escasez de la oferta disponible en Inglaterra, que de una ausencia de demanda. Hasta el final de la centuria, son escasos los curiosos y bibliofilos británicos que se aventuran a comprar libros en España. David Steuart fue uno de éstos.

El escocés David Steuart nació el 20 de septiembre de 1747 en el seno de una familia de origen noble de la región de Perth. Como segundón, se dedicó desde muy joven al comercio ${ }^{5}$. En 1764 comenzó a trabajar en Edimburgo en la empresa John Coutts \& Co., pasando en 1767 a su asociada londinense Herries, Cochrane \& Co., más comercial, que acabaría denominándose Herries \& Co. El negociante Robert Herries (1730-1815) estaba especializado, desde comienzos de los sesenta, en la importación de vinos y brandy desde Barcelona a Inglaterra. Steuart, tras obtener una participación en la compañía, se encaminó a Barcelona, vía París, en febrero de 1768, encontrándose en la capital catalana a mediados de ese año.

Desde Barcelona escribe, con fecha 16 de julio de 1768, a Sir William Forbes, su antiguo jefe en John Coutts \& Co., residente en Edimburgo:

2 Thomas-Frognall DIBDIN, The Bibliomania, or book madness, containing some account of the history, symptoms, and cure of this fatal disease, in an epistle to Richard Heber, 1809. Muy aumentado en subsiguientes ediciones.

3 El catálogo de venta de su biblioteca lleva el título Bibliotheca Croftsiana. A catalogue of the curious and distinguished library of the late Reverend... Thomas Crofts... Which will be sold by auction, by Mr. Paterson... on Monday, April 7, 1783 and the forty-two following days, London, $1783,8^{\circ}$, XVI $+420 \mathrm{pp}$. El escritor y bibliófilo William Beckford, uno de los hombres más ricos de la Inglaterra de su tiempo, adquirió en esta subasta un manuscrito catalán acerca de los atributos de los ángeles (vid. A. HOBSON, «William Beckford's Library», en The Connoisseur 191 (1976), pp. 298-305). Acerca de la colección del reverendo Crofts puede verse P. CÁTEDRA y V. INFANTES, Los pliegos sueltos de Thomas Croft (Siglo XVI), Valencia, 1983, 2 vols., puesto al día por V. Infantes, «Balance bibliográfico y perspectivas críticas de los pliegos sueltos poéticos del siglo XVI», en Varia Bibliographica. Homenaje a José Simón Díaz, Kassel, Reichenberger, 1987, pp. 375-385.

4 El sacerdote anglicano John Bowle (1725-1788), que nunca visitó España, dio a luz su célebre edición anotada del Quijote en 1781. Acerca de su biblioteca particular puede consultarse R. MERRITT COX, «The Library of the Reverend John Bowle: Revelations in English Hispanism», en Studies in Honour of Gerald E. Wade, Madrid, José Porrúa, 1979, pp. 23-34.

5 La correspondencia de la familia Steuart de Dalguise se conserva en la Scottish Record Office (Edimburgo), legajo GD 38. 
«España me empieza a gustar mucho, aunque todavía no me he acostumbrado a muchas de sus costumbres, algunas de las cuales no dejan de parecer muy extrañas al extranjero. El clima, estoy convencido, es uno de los mejores del mundo, aunque presenta el mismo inconveniente que el resto de los países cálidos, en que los insectos no paran de molestar, lo que comienza a ser un problema. Le suplico salude de mi parte a $\mathrm{Mr}$. Stephen y familia, y a Mr. Hunter, y que le diga a éste último caballero que muy pronto le escribiré personalmente. Temo que se haya ofendido por no haberlo hecho hasta ahora, pero mis ratos de ocio, los he ocupado todos en estudiar el español, lo que tiene gran importancia para mí en estos momentos ${ }^{6}$. Según el viajero Henry Swinburne, las compañías extranjeras afincadas en Barcelona estaban especializadas en el comercio de vino, brandy, sal y aceite, que embarcaban rumbo a sus países no en la capital, sino en los pequeños puertos a lo largo de la costa. Todas ellas tenían agentes y factorías en Reus, donde almacenaban el excelente brandy fabricado por los cartujos, al cual, para oscurecer su palidez y hacerlo así más atractivo, se le añadían posteriormente otros alcoholes en Guernsey y Holanda ${ }^{7}$.

Por la carta que escribió a su padre John Steuart en Barcelona el 17 de enero de 1769, sabemos que el producto de esos primeros meses no alcanzó lo que esperaba: «No hemos tenido tanta suerte en los negocios este año como es usual, ni como era razonable suponer hace cuatro meses. No obstante, espero que, en general, todavía saldremos bien, pues hemos de sobrellevar los malos años con los buenos» ${ }^{8}$.

Un año después, el 17 de febrero de 1770, escribía a su padre desde Barcelona: «Acabo de regresar de una excursión por la costa, donde tenía que resolver cierto negocio para nuestra empresa. Llegué hasta Valencia, que está a siete días de viaje de aquí. Las únicas molestias que tuve en mi

6 D. Steuart a W. Forbes, Barcelona 16.07.1768: «I begin to like Spain pretty well, though I am not yet reconciled to a great number of their customs, some of which must appear very odd to a stranger. This climate I am persuaded, is one ot the best in the World, though it has the same inconveniency as other warm Countries, of being pestered with Insects, which begin already to be very troublesome. I beg my respects to $\mathrm{Mr}$ Stephen and his family and Mr Hunter and that you will be so good as tell this last gentleman that I shall very soon do myself the pleasure of writing him; I am afraid he will have taken amiss my not having done so before now, but my leisure hours have been taken up in studying the Spanish, which is of great consequence to me at present.» (National Library of Scotland, legajo 4796/2, carpeta 6).

7 H. SwinbURNe, Travels through Spain in the Years 1775 and 1776, Dublin, 1779, vid. especialmente las Cartas IX y X.

8 D. Steuart a J. Steuart, Barcelona 17.01.1769: «We have not been quite so lucky in trade this year as usual, nor indeed as we had reason to imagine about four months ago - however I hope on the whole we shall do well enough yet \& we must take the bad years with the good.» (Scottish Record Office, legajo GD 38/2 carpeta 10, 107). 
viaje fueron consecuencia de las malas posadas y del calor excesivo, que supera al de Inglaterra en los meses de julio y agosto (...) Ya no padezco ninguno de los malos efectos de mis fiebres» ${ }^{9}$.

El 22 de septiembre del mismo año escribía a su padre John Steuart: "Querido padre: en la carta que escribí a mi hermano al comienzo de este mes, acusé recibo de la de usted del 28 de julio, pidiéndole que le dijese que no le escribiría hasta terminar de hacer nuestro balance, como es ahora el caso, ascendiendo la parte que me corresponde de nuestros beneficios a doscientas cincuenta libras esterlinas. Espero ganar un poco más el año que viene, pues me han encargado la administración de la casa, que hasta aquí siempre se ha hecho con ganancia. El complemento está en relación con los beneficios y supuso el año pasado más de setecientas libras esterlinas. Veo que usted ha pagado los libros que mi hermano me envió. Lo siento, pues no quiero causarle ninguna molestia y usted ya ha hecho por mí más de lo que merezco. Me alegro de que mi madre haya recibido los pañuelos que le mandé. Espero que no piense en regalar alguno de ellos y que los use ella. Aquí son muy baratos y no cuestan más de media corona cada uno (...) Me he librado de las fiebres este verano, aunque me han amenazado varias veces. El único remedio que he tomado han sido los baños fríos, que he encontrado sumamente beneficiosos» ${ }^{10}$.

No sabemos cuándo salió de España, a donde ya nunca volvería, probablemente hacia julio de 1771 , en que se convirtió en socio de un tal Mr. Park, comerciante asentado en el puerto bretón de Roscoff ${ }^{11}$. Viajó a Es-

9 D. Steuart a J. Steuart, Barcelona 17.02.1770: «I am just now returned from a jaunt I had been on the coast where I had some business to manage for the house; I was as far as Valencia which is seven days journey from this - the only inconveniency I found in my journey was from the bad inns, \& the excessive heat of the weather which was warmer than it is in England during the months of July and August. (...) I now feel none of the bad effects of my Ague.» (Scottish Record Office, legajo GD 38/2 carpeta 13, 3).

10 D. Steuart a J. Steuart, Barcelona 22.09.1770: «Dear father: In a letter I wrote my brother the beginning of this month I acknowledged the receit of your favor of the 28 July \& desired he would tell you that I delayed writing you till our books were balanced which is now the case \& my share of our profits ammounts to a little more than $£ 250$ Sterling. I hope I shall make a little more next year as I have the housekeeping which has hithertoo yeilded profit. The allowance is so much bent on the profits $\&$ amounted last year to above seven hundred pounds Sterling.

I observe you have paid for the books that my brother sent me for which I am sorry as I wish it may not incomode you \& you have already done more for me than I merit. I am glad to see that my mother has received the few handkerchifs I sent her. I beg she would not think of giving any of them away but make use of them herself - they are very cheap here \& don't cost above half a crown a piece. (...) I have been quite free from the Ague this summer tho'it threatened me several times. The only remedy I take for it is the cold bath from which I have found great benefit.» (Scottish Record Office, legajo GD 38/2 carpeta 13, 19).

11 D. Steuart a J. Steuart, Gadgirth 28.07.1771 (Scottish Record Office, legajo GD $38 / 2$ carpeta 13,31 ). 
cocia en septiembre de 1774 , pero regresó a Francia, esta vez a Nantes, al año siguiente. En 1776 se afincó ya de modo definitivo en Edimburgo, donde fundó la banca privada Allan \& Steuart, que abandonaría a finales de agosto de 1790. David Steuart se fue mezclando cada vez más en la política local de la capital escocesa, sirviendo como su alcalde, durante dos años, a partir de octubre de 1780. Fue nombrado, asimismo, presidente de la cámara de comercio de Edimburgo en 1787 y 1790.

En los años ochenta, Steuart hizo una gran fortuna, pero le afectó gravemente la bancarrota de las principales destilerías escocesas del año 1788. En 1793 se pasó al comercio de vinos, mejorando poco a poco su situación económica, hasta sufrir un nuevo revés a mediados de 1797, llegando incluso a ser encarcelado por deudas a finales de 1799. Los trámites de su declaración de bancarrota duraron hasta mediados de 1802. Steuart continuó su actividad como comerciante de vinos hasta el año 1815, pero nunca resolvió del todo sus problemas económicos. Falleció el 19 de mayo de 1824.

A consecuencia de una orden de embargo recibida durante el proceso de su bancarrota, David Steuart se vio obligado a subastar su colección de libros. El catálogo de venta - del que se ha conservado un único ejemplar - confeccionado con vistas a la subasta lleva el orgulloso y descriptivo título $A$ Catalogue of a small but very select collection of books in which are to be found some of the finest specimens of typography extant, from the first attempts on wooden blocks, until the present time; particularly from the presses of John Guttemberg, J. Fust \& P. Schoeffer, Lawrence Koster, Nicholas Jenson, Vindeline de Spire, C. Sweynheim \& A. Pannartz, William Caxton, Wynken de Worde, and many of the other Printers who flourished in the Fifteenth Century; as well as of Aldus, Elzevir, Stevens, Vostre, Royal Press (Paris), Giolito, Giunti, Grafton, Feild, Tonson, Foulis, Ibarra, Baskerville, Bodoni, Barbou, Didot, Bensley, Bulmer, And other Modern Printers ${ }^{12}$. La subasta de los libros, organizada por el librero Cornelius Elliot en su local de Cross, en Edimburgo, dio comienzo el 18 de mayo de 1801 , a las doce de la mañana, repitiéndose a la misma hora en los once días siguientes.

El catálogo de venta señala 958 lotes, distribuidos a lo largo de las doce sesiones. Para cada sesión de la subasta se ordenan los lotes según

12 Conservado en la New York Public Library. Brian Hillyard, bibliotecario de la National Library of Scotland, al cual agradezco la ayuda prestada a lo largo de mi investigación, lo ha publicado en facsímil, precedido de un estudio introductorio del que he sacado los pertinentes datos biográficos para situar las cartas españolas de Steuart: B. HILlyard, David Steuart, Squire. An Edinburgh Collector. The 1801 Sale Catalogue of part of his Library reproduced from the unique copy in New York Public Library with an introduction essay, Edinburgh Bibliographical Society in Association with The National Library of Scotland, 1993. 
su formato, bajo los tres epígrafes Infolios, Cuartos y Octavos e inferiores. En ocasiones la referencia a las obras se acompaña de un comentario relativo a la importancia del libro, su encuadernación o su estado de conservación, comentario que parece redactado o inspirado por el propio Steuart. Los lotes, según especifica una de las condiciones de la subasta, pudieron ser examinados por los interesados el viernes $15 \mathrm{y}$ el sábado 16 de mayo y todas las mañanas los días de subasta.

Brian Hillyard, en su introducción a la edición facsímil del catálogo de venta, caracteriza a David Steuart como bibliófilo ${ }^{13}$. De ello no cabe duda: entre las 958 obras a subastar se registran treinta y cuatro incunables -entre ellos las Biblias maguntinas de los años 1462 y 1472-. Entre los impresores modernos cabe señalar quince obras impresas por John Baskerville y treinta y cuatro por Giambattista Bodoni ${ }^{14}$. La circunstancia de que se señalase con un asterisco - en veinticuatro ocasiones- determinadas obras, que no podían examinarse libremente en la librería de Elliot y que, para ser vistas, había que solicitarlo expresamente al librero, parece apuntar, según piensa Hillyard, a una imposición del bibliófilo Steuart, poco dispuesto a soportar que toqueteasen sus mejores libros - así en el caso de las dos Biblias maguntinas antes citadas-.

Los libros españoles o que tienen alguna asociación con España en el catálogo de venta de la biblioteca de David Steuart son 144 en 234 volúmenes.

Bajo el epígrafe «Literatura» hemos clasificado 40 obras -el 27,7\% del conjunto aquí estudiado-: de entre ellas, 12 bajo «Poesía» y 19 bajo «Prosa». Entre los libros de poesía destaca la presencia del Parnaso español, la manejable antología poética que Juan José López de Sedano publicó entre 1768 y 1778. Si no comenzó a adquirir sus volúmenes durante su estancia en España - no sabemos por qué le falta el volumen primero de esta obra-, es posible que tuviera noticia entonces de la salida al mercado de esta novedosa colección de poetas de los siglos XVI y XVII. Su interés por los grandes nombres de la poesía barroca, lo manifiesta la presencia de las obras de Lope de Vega, Góngora y Quevedo. La poesía del siglo XVI está representada por las obras de Garcilaso y Boscán y una traducción española del Orlando furioso de Ariosto. La presencia de las Academias morales de las Musas de Antonio Enríquez Gómez (Segovia, fines del siglo XVI-Holanda, 1622), sin duda está ligada a la curiosidad de Steuart por todo tipo de obras relacionadas con los judíos de origen español. Es muy posible que adquiriese en España su edición de las Fábulas de Eso-

13 B. HillyaRd, ob. cit., pp. 21-33.

14 B. Hillyard ha documentado la historia de la relación entre Steuart y el impresor parmesano en «Parma and Edinburgh: Some letters relating to the European booktrade at the end of the eighteenth century», Bulletin du bibliophile 2 (1992), pp. 330-364. 
po - que no hemos identificado, pero que probablemente fuese dieciochesca-, y que su adquisición tuviese un motivo utilitario: profundizar en su conocimiento del español.

Entre la prosa de ficción destaca la importante colección cervantina. Steuart posee una edición de La Galatea, dos de las Novelas ejemplares - la príncipe de 1613, y la preparada por el converso refugiado en Inglaterra Pedro Pineda-, tres ediciones del Quijote - la de La Haya del año 1744, la de la Academia de 1780 y una francesa de 1776- y una del Persiles y Segismunda. La bibliofilia de Steuart se manifiesta aquí en una doble vertiente: por un lado en su valoración de las magníficas ediciones ilustradas del Quijote y el Persiles - que encuaderna lujosamente-, por otro en su interés en adquirir ediciones tempranas de las obras de Cervantes. A comienzos de febrero de 1793, Steuart propuso al tipógrafo e impresor parmesano Giambattista Bodoni llevar a cabo una edición del Quijote en español, ofreciéndose a adquirir cincuenta ejemplares de la tirada. En carta de 6 de abril de 1793, le sugiere que la edición se haga en dos volúmenes en folio, basándose en la edición de la Academia, impresa por Ibarra, de 1780, asegurándole que él, en todo caso, está dispuesto a comprarle cien ejemplares. A Bodoni el proyecto le ilusionó y se lo comunicó a su mecenas José Nicolás de Azara, quien arrojó un jarro de agua sobre la propuesta de Steuart: «No creo que sea conveniente imprimir el Quijote en español, porque habría que hacerlo más magnífico que el de Ibarra y, en tal caso, los gastos serían inmensos sin ninguna esperanza de recuperarlos, pues los españoles preferirán su edición con un pretexto u otro. A esto se añade el privilegio y la ley que prohíbe la introducción de libros en español impresos fuera del Reino. Por lo que respecta a los otros libros que quiere el señor Stuart, usted puede hacer como le convenga» ${ }^{15}$. No obstante, Bodoni no abandonó la idea y a finales de 1794 pensó que el proyecto podría llegar a realizarse ligándolo al planeado matrimonio entre el heredero del ducado parmesano y la infanta española María Luisa, hija de Carlos IV. Bodoni le plantea a Steuart hacer una tirada de sólo cien ejemplares, en cuatro volúmenes, de los que cada uno se quedaría con cincuenta. La respuesta final de Steuart le llega al impresor en su carta del 3 de noviembre de 1794: «El estado actual de Europa no me permite pensar en el Don Quijote, pero llegará el día en que usted pueda llevar a cabo con éxito

15 J. N. de Azara a G. Bodoni, Roma 06.03.1793: «Non credo che convenga la stampa del Quixote in Spagnuolo, perchè bisognarebbe fare qualche cosa di più magnifico dell edizione di Ibarra, ed in tale caso la spessa sarebbe enorme senza speranza di rifarsi, perchè i Spagnuoli si atterrano sempre alla loro edizione con un pretesto o con un altro. A ciò si aggiunge il privilegio e la legge di non ammettere i libri spagnuoli stampati fuori del Regno. Per li altri Libri che domanda il Signore Stuart lei lo puole servire come vuole» (en A. Ciavarella, De Azara-Bodoni, II, Parma, Museo Bodoniano, 1979, p. 81). 
este proyecto» ${ }^{16}$. En la circunstancia de una Europa en que arrecia la guerra entre las monarquías y la República francesa, con las consiguientes dificultades para el comercio, no tiene sentido comercial la aventura de un Quijote tirado sólo para un pequeño número de desperdigados bibliófilos.

La presencia del Amadís de Gaula podría estar relacionada con la afición de Steuart por el Quijote. Otro de los sectores representados es el de la novela picaresca: se encuentran presentes las obras de Mateo Alemán, López de Úbeda y Estebanillo González. Las obras de Jerónimo de Contreras y Francisco de Quintana representan el género de la novela sentimental-pastoril de la segunda parte del siglo XvI. Dentro de la novela contemporánea, Steuart adquirió la traducción inglesa de Fray Gerundio y la traducción al español de la obra de Lesage por el padre Isla - del cual posee, asimismo, su traducción del Compendio de la historia de España del padre Duchesne-. La Historia de Bertoldo de Giulio Cesare della Croce, en edición barcelonesa de 1769 (n. ${ }^{\circ} 23$ de nuestra lista), la debió adquirir Steuart durante su estancia allí en aquellos primeros momentos de su introducción al castellano.

El tercer subgrupo de obras clasificado bajo el epígrafe «Literatura», lo compone un conjunto de ediciones bodonianas que se han incluido entre los libros españoles de Steuart por su asociación con España, especialmente a través del mecenazgo que el embajador de España en la Roma papal, José Nicolás de Azara, ejerció respecto al impresor y tipógrafo afincado en Parma Giambattista Bodoni. Azara costeó las ediciones de la serie de los clásicos grecolatinos de la imprenta particular bodoniana, paralela a la Stamperia reale. Steuart posee dos ejemplares del Horacio de 1791 $\left(n .^{\circ} 34\right.$ y 35) y tres ejemplares del Virgilio de $1793\left(n^{\circ} 38,39\right.$ y 40), algunos de los más logrados experimentos de la tipografía neoclásica ${ }^{17}$. La Stamperia reale parmesana, a cuyo frente estaba Bodoni, también se encargó de la impresión de tres oraciones fúnebres a la muerte del rey de España Carlos III (n. 127,128 y 129). La traducción al italiano -por F. Milizia- de la Introducción a la historia natural y geografía física de España de Guillermo Bowles, editada por José Nicolás de Azara, fue producto de un encargo de éste (n. $\left.{ }^{\circ} 132\right)$.

El grupo de obras bajo el epígrafe «Diccionarios y obras de filología»

16 D. Steuart a G. Bodoni, Londres 03.11.1794: «L'état actuel de l'Europe ne me permet pas de penser au Don Quichotte, mais le tems viendra quand vous pourrez exécuter ce project [sic] avec succès» (en B. Hillyard, art. cit., p. 356). A. Boselli resumió la historia de la frustrada edición del Quijote bodoniano en «Quello che G. B. Bodoni non stampò (Spigolature dal carteggio bodoniano)», Gutenberg Jahrbuch (1934), pp. 231247, especialmente en pp. 242-244.

17 Para la relación entre Azara y Bodoni, véase G. SÁNCHEZ EsPINOSA, La biblioteca de José Nicolás de Azara, Madrid, Calcografía Nacional, 1997, especialmente las pp. 49-53. 
-12 obras, que suponen el $8,3 \%$ del total-, tiene una marcada finalidad utilitaria. Steuart debió servirse de ellas tanto para mejorar su conocimiento del castellano con vistas a utilizarlo en los negocios, como para profundizar en la comprensión de las obras literarias en este idioma. Destaca el grupo formado por la Gramática, la Ortografía y el Diccionario de la Real Academia (n. ${ }^{\circ} 48,50$ y 41). También es significativo su interés por el catalán -no en vano es Barcelona la base comercial del escocés en España- Steuart posee el diccionario trilingüe de Pere Lacavalleria $\left(n .^{\circ} 42\right)$ y el Tratat de adages, y refranys valencians del año 1736 de Carlos Ros (n. ${ }^{\circ}$ 52), sin duda comprado en España. Otros libros en catalán son los n. ${ }^{\circ} 56,59,62,64,65$ y 89. Esta última obra, las Instruccions per la ensenyansa de Minyons de Baldiri Rexach, debió adquirirse con objeto de mejorar su conocimiento de dicha lengua.

Entre las escasas obras que tratan de las bellas artes destaca el Viaje de España del illustrado Antonio Ponz, que debió poseer -incompletoen su segunda edición, ya con el nombre de su autor.

El conjunto de libros agrupado bajo el epígrafe «Religión, pensamiento y educación», nos revela alguna peculiaridad de Steuart como coleccionista de libros españoles. Reunió libros de temática católica, protestante y judía. Entre los de religión católica - diez en total-, destaca tanto su interés por Fray Luis de Granada, del que tiene dos obras (n. ${ }^{\circ} 60$ y 61$)$ y del que señala que «el estilo de este autor es un modelo de lengua española», comentario usual en las retóricas ilustradas, como su curiosidad no exenta de ironía por reunir algunas piezas de lo que para un protestante ilustrado escocés serían quintaesencias de la superstición católica española. En este sentido hay que leer sus notas al Kempis (n. ${ }^{\circ}$ 62) - «la portada promete 320 días de remisión de las penas del purgatorio a todo aquel que lea o escuche hasta el final un capítulo de este libro»- y al Joyell preciós (n..$^{\circ}$ 64) - «este libro ha pasado por las manos de la Inquisición, como manifiesta el certificado del calificador, que ha tachado muchos pasajes»-El El Index librorum prohibitorum del cardenal Sandoval y Rojas (n. $\left.{ }^{\circ} 143\right)$ debió verlo, sobre todo, como una rica fuente de noticias literarias. La presencia de la obra de Eugenio de Robles sobre Cisneros (n. ${ }^{\circ} 123$ ), puede obedecer a su curiosidad por las rarezas litúrgicas, en este caso el oficio mozárabe toledano.

Los libros de temática judaica son ocho. La mayoría de ellos son libros de la liturgia sefardí impresos en Amsterdam. Moses Méndez fue un conocido miembro de una influyente familia sefardí afincada en Inglaterra. Steuart también poseyó una edición española de Los Diálogos de amor de León Hebreo (n..$^{\circ}$ ) y las anteriormente citadas Academias morales de las Musas de Antonio Enríquez Gómez (n. ${ }^{\circ} 3$ ).

Un tercer subgrupo dentro de las obras de religión está constituido por textos de adscripción reformista o protestante. Tres de ellas están relacio- 
nadas con la figura de Félix Antonio de Alvarado, sevillano refugiado en Londres a comienzos del XVIII $\left(\mathrm{n}^{\circ} 74,75 \mathrm{y} 76\right)$, las dos primeras son libros de liturgia de la iglesia anglicana; la última de estas obras es una exposición de las doctrinas de los cuáqueros. Se incluyen aquí dos ediciones de la Biblia del Oso de Casiodoro de la Reina, la original de 1569 (n..$^{\circ} 77$ ) y la pirata de $1622\left(\mathrm{n}^{\circ}\right.$ 78), y dos traducciones debidas a Cipriano de Valera. Este heterogéneo conjunto de libros protestantes y judíos en español, espigados fuera de España, nos hace percibir el carácter ecléctico del coleccionismo de Steuart, al que no deja de atraer el libro curioso y raro.

La obra del benedictino Benito Jerónimo Feijoo, el más conocido publicista de la Ilustración española, está perfectamente representada entre los libros de Steuart. Poseyó el Teatro crítico universal $\left(\mathrm{n}^{\circ}{ }^{85}\right.$ ) en ocho volúmenes, las Cartas eruditas ( $\mathrm{n}^{\circ}{ }^{\circ} 83$ ) en cinco y las Cartas apologéticas (n. ${ }^{\circ}$ 84). Son ediciones de los años sesenta, indudablemente adquiridas o comenzadas a adquirir durante su estancia en Barcelona. Podemos pensar que alguien allí le recomendaría su lectura y ésta debió satisfacerle, llevándole a la compra del resto de las obras de dicho autor. Es posible que el Examen de ingenios de 1768 (n. $\left.{ }^{\circ} 88\right)$ también fuese adquirido por él en España.

Los libros agrupados bajo el epígrafe «Historia» son 36, lo que supone el $25 \%$ de total aquí estudiado. Destaca su interés por los de temática americana (n. ${ }^{\circ} 93,98,99,101,102,103,107,109,112,114,115,118$, 120 y 124). Encontramos una enorme variedad de textos impresos a lo largo de tres siglos: crónicas, historias de la conquista y reevaluaciones de la colonización - Raynal, Nuix - Resalta la presencia de Bartolomé de las Casas (n. ${ }^{\circ} 98$ y 99). Este nucleo histórico de tema americano se completa con una serie de libros de historia natural y viajes por América producto de la nueva aproximación del dieciocho a la geografía y a las ciencias (n. ${ }^{\circ} 133,135,139$ y 140), a los que podría agregarse como curioso antecedente el Tractado de las drogas y medicinas de las Indias Orientales de Cristóbal Acosta (n. ${ }^{\circ}$ 141).

De los Diálogos de medallas de Antonio Agustín, obra entonces fundamental para todo anticuario o aspirante a tener un barniz de ello, tiene tres ediciones (.$^{\circ}$ 90, 91 y 92). La Noticia de la Gran Bretaña, con relación a su estado antiguo y presente $\left(\mathrm{n}^{\circ}{ }^{\circ} 121\right)$, traducida por Nicolás de Ribera y aparecida en 1767, debió ser adquirida en España.

Entre los libros agrupados bajo el epígrafe «Economía y política», destaca un volumen facticio (n..$^{\circ} 131$ ), en formato cuarto, de papeles españoles aparecidos con motivo de la Guerra de Sucesión. Es imposible saber si Steuart adquirió estos treinta pliegos ya encuadernados conjuntamente o los fue comprando sueltos y los envió a encuadernar él mismo. La obra de Blainville (n. $\left.{ }^{\circ} 130\right)$ es otro producto satírico de la Guerra de Sucesión, por 
la que debió sentir bastante interés, como se deduce del hecho de poseer dos ejemplares de los Comentarios a la guerra de España del marqués de San Felipe (n. ${ }^{\circ} 94$ y 95). La Correspondencia de la moneda de Cataluña a la de Castilla (n. ${ }^{\circ}$ 126), obra de interés práctico para un hombre de negocios afincado en Barcelona, debió ser adquirida, sin duda, en España, al considerarse imprescindible en los negocios.

David Steuart, que pasó en su juventud tres años en España, entre mediados de 1768 y julio de 1771, debió conservar toda su vida el amor y el interés por la lengua, la literatura, la historia y la cultura españolas. Este conjunto de 144 libros españoles extraído del catálogo de venta de su biblioteca así lo atestigua.

\section{NOTA PREVIA}

En la lista de los libros españoles de D. Steuart que ofrecemos a continuación, siempre que no se indica formato se debe entender que es octavo o inferior. Hemos traducido los comentarios bibliográficos de Steuart, que aparecen en cursiva.

\section{LISTA DE LOS LIBROS ESPAÑOLES DE DAVID STEUART}

\section{LiteratURA}

\section{I.1. Poesía}

1. Orlando Furioso traducido en Espanol, Lyons $15504^{\circ}$.

ARIosto, Ludovico, Orlando furioso, Lyon, Gulielmo Roville en casa de Mathias Bonhome, $1550,4^{\circ}$.

2. Obras de Boscan y algunas de Garcilaso de la Vega, Antwerp 1556

Las obras de Boscan y algunas de Garcilasso de la Vega..., Anvers, Martin Nucio, $1556,12^{\circ}$.

3. Academias Morales, por $\mathrm{Ant}^{\circ} \mathrm{Hen}^{2}$ Gomes, $16424^{\circ}$

ENRíQueZ GómeZ, Antonio, Academias morales de las Musas, Estampado en Bordeaux, por el Señor Pedro de la Court, 1642, $4^{\circ}$.

4. Las Faulas de Isop ${ }^{18}$

18 Debe tratarse de una edición dieciochesca de la obra que no podemos identificar. La biblioteca de la Faculty of Advocates de Edimburgo posee la edición Faulas, y vida de Isopo, con las de otros autores: traducidas por su orden nuevaménte de Latin en 
5. Obras de Dn Luis de Gongora, Madrid 1654

GóngORA Y ARGOTE, Luis, Todas las obras de Don Luis de Gongora en varios poemas. Recogidos por Don Gonzalo de Hozes y Cordova, Madrid, Imprenta Real, $1654,4^{\circ}$.

6. Obras de $\mathrm{D}^{\mathrm{n}}$ Luis de Gongora, sin portada

7. Poesias de Pablo Gonzalez de Andrada Coimbra 1658

GonZAlveZ DE ANDradA, Paulo, Varias poesias, Coimbra, M. Dias, 1658, $8^{\circ}$.

8. El Parnaso Espanol, (falta el primer vol.) 8 vol. Madrid 1770

LóPEZ DE SEDANo, Juan José, Parnaso español. Coleccion de poesías escogidas de los mas célebres poetas castellanos, Madrid, Por D. Joaquin de Ibarra [tomos 1-5, 1768-1771]. Por D. Antonio de Sancha [tomos 6-9, 1772-1778], 9 vols., $8^{\circ}$.

9. Obras de $\mathrm{D}^{\mathrm{n}}$ Francisco de Quevedo, 3 vol. Brussels $16604^{\circ}$.

QUEVEDO VIllegas, Francisco de, Obras de don Francisco de Quevedo Villegas, En Brusselas, Dela emprenta de Francisco Foppens, 1660-1661, 3 vols., $4^{\circ}$.

10. El Parnaso Espanol, por Quevedo, Madrid $17134^{\circ}$.

Quevedo y Villegas, Francisco, El Parnaso español: Monte en dos cumbres dividido con las nueve musas castellanas. Donde se contienen poesias de Don... Salen ahora añadidos con adorno de unas Dissertaciones a cada una de las Musas..., En Madrid, En la Imprenta de Manuel Román. A costa de los Herederos de Gabriel de Leon, Año 1713.

11. Rimas de Lope de Vega Carpio, manchado, Huesca 1623

VeGa CARPIO, Lope Félix de, Rimas de Lope de Vega Carpio..., en Huesca, por Pedro Bluson impressor de la Universidad, Año 1623, $16^{\circ}$.

12. Las Obras de Publio Virgilio, Vallod. $16014^{\circ}$.

Virgilio, Las obras de Publio Virgilio Maron, traduzido en prosa Castellana por Diego Lopez..., Valladolid, Por Francisco Fernandez de Cordova, 1601, $4^{\circ}$.

I.2. PROSA

13. La Vida de Guzman de Alfarache, Tarrag. 1603

AlEMÁn, Mateo, Primera parte de la vida del picaro Guzman de Alfarache, Tarragona, en casa de Felipe Roberto, 1603, $8^{\circ}$.

14. Amadis de Gaula, segunda edición, muy rara, Sevilla 1586 fol.

Los quatro libros de Amadis de Gaula, nuevamente corregidos e impresos, Sevilla, por Fernando Diaz a costa de Alonso de Mata, 1586, fol.

Castellano por Don Juan de Lama. Con el aumento de la Perla de las dos lenguas, Latina y Hespañóla, que es el acénto de ambas: y la ortografia moderna... (Madrid, Antonio Sanz, 1738, $8^{\circ}$ ), procedente de la biblioteca del marqués de Astorga -adquirida por la Advocates' Library en 1825-. 
15. La Galetea por Miguel de Cervantes, Barcelona 1718

Cervantes SaAvedra, Miguel de, Los seys libros de la Galatea, en Barcelona, Por Sebastian de Cormellas, Año $1618,8^{\circ}$.

16. Cervantes Novelas Exemplares, primera edición, Madrid $16134^{\circ}$.

Cervantes Saavedra, Miguel de, Novelas exemplares de Miguel de Cervantes Saavedra..., En Madrid, Por Juan de la Cuesta, 1613, $4^{\circ}$.

17. Novelas de Cervantes, 2 vol. Hague $1739^{19}$

Cervantes SaAvedra, Miguel de, Novelas exemplares de Miguél de Cervantes Saavedra: dirigidas á la Exelentissima señora condesa de Westmorland, En Haya, A Costa de J. Neaulme, 1739, 2 vols., $8^{\circ}$.

18. Vida y Hechos de $\mathrm{D}^{\mathrm{n}}$ Quixote, con estampas, 4 vol. Hague 1744

Cervantes Saavedra, Miguel de, Vida y Hechos del Ingenioso Hidalgo Don Quixote de la Mancha..., En Haia, por P. Gosse y A. Moetjens, 1744, 4 vols., $8^{\circ}$.

19. Les Principales Aventures de $\mathrm{D}^{\mathrm{n}}$ Quichotte, Liege $17764^{\circ}$.

Cervantes SaAvedra, Miguel de, Les Principales Aventures de l'admirable Don Quichotte, A Liège, Chez J. F. Bassompierre Imprimeur de Son Altesse, 1776, $4^{\circ}$.

20. El Ingenioso Hidalgo $\mathrm{D}^{\mathrm{n}}$ Quixote de la Mancha, magníficamente encuadernado por Scott, 4 vol. Madrid $17804^{\circ}$.

Este ejemplar fue especialmente seleccionado por el Conde de Campomanes y está ilustrado con la primera tirada de las láminas ${ }^{20}$.

Cervantes SAAVEDRA, Miguel de, El Ingenioso Hidalgo Don Quixote de la Mancha; compuesto por Miguel de Cervántes Saavedra. Nueva Edicion Corregida por la Real Academia Española, En Madrid, Por Don Joaquin Ibarra Impresor de Cámara de S.M. y de la Real Academia, 1780, 4 vols., $4^{\circ}$.

21. Persiles y Sigismunda, buena encuadernación, cantos dorados. Se trata de una de las mejores obras de Ibarra, Madrid 1781

Cervantes SaAvedra, Miguel de, Trabajos de Persiles y Sigismunda. Historia setentrional, Madrid, En la Imprenta de Sancha, 1781, 2 vols., $8^{\circ}$.

19 La edición estuvo al cuidado de Pedro Pineda, que había tenido a su cuidado la edición londinense del Quijote sufragada por lord Carteret.

20 En Waddesdon Manor, en la biblioteca que fue del barón Ferdinand de Rothschild, se conserva un ejemplar de esta obra que fue regalado en su día por Eugenio Izquierdo a Mme. De Bure y lleva una nota que afirma que las estampas habían sido especialmente escogidas entre las de la primera tirada (A. R. A. HOBSON, «Unfamiliar Libraries V: Waddesdon Manor», The Book Collector 8 (1959), p. 133). James Scott, activo entre 1773 y 1792, fue el más célebre encuadernador del Edimburgo de su tiempo. De un rococó a la Chippendale, pasó, hacia 1776, a un neoclasicismo influido por el arquitecto Robert Adam, cuyos motivos más característicos son fasces, trofeos, corazas, urnas y banderas. A mediados de 1781 se le nombró encuadernador de la Sociedad de anticuarios de Escocia. Véase J. H. Loudon, James Scott and William Scott, bookbinders, Scolar Press-National Library of Scotland, 1980. 
22. Selva de Aventuras par Hieronimo de Contre, Salam. 1573

JeRónimo DE Contreras, Selva de aventuras, Salamanca, P. Laso, 1573, $8^{\circ}$.

23. Historia de Bertoldo, Barcel. 1769

CROCE, Giulio Cesare della, Historia de la vida, hechos y astucias del rustico Bertoldo, la de Bertoldino su hijo, y la de Cacaseno su nieto. Traducida del Toscano por Don Juan Bartholome, Barcelona, por Francisco Suriá, 1769, $8^{\circ}$.

24. Vida y Hechos de Estevanillo Gonzalez, Antwerp $16464^{\circ}$.

GonZÁlez, EstebAn, La vida i hechos de Estevanillo Gonzalez, Hombre de buen humor. Compuesto por el mesmo, En Amberes, En casa de la Viuda de Juan Cnobbart, $1646,4^{\circ}$.

25. Friar Gerund, 2 vol. Lond. 1772

ISLA, José Francisco de, The history of the famous Preacher Friar Gerund de Campazas: otherwise Gerund Zotes. Translated from the Spanish, London, T. Davies and W. Flexney, 1772, 2 vols., $8^{\circ 21}$.

26. Aventuras de Gil Blas de Santillana, 4 vol. Madrid $17874^{\circ}$.

LeSAGE, Alain-René, Aventuras de Gil Blas de Santillana, robadas a España y adoptadas en Francia por Monsieur Le Sage, restituidas a su patria y a su lengua nativa por un español zeloso, que no sufre se burlen de su nación, Madrid, Manuel González, 1787-1788, 4 vols., $4^{\circ 22}$

27. La Picara Justina, con el frontispicio, rara, Brussels 1708

LÓPEZ DE UBEDA, Francisco, Libro de entretenimiento de la Picara Justina en el qual debaxo de Graciosos discursos se encierran provechosos avisos, Brucellas, en casa de Olivero Brunello, 1608, $4^{\circ}$.

28. Enganos de Mugeres por $\mathrm{D}^{\mathrm{n}}$ Miguel de Montreal, Madrid $17094^{\circ}$.

Montreal, Miguel de, Engaños de Mugeres, y Desengaños de los Hombres; divididos en quatro discursos historicos, politicos y morales... A la fin va añadida la Novela de los tres Maridos burlados, Madrid, Manuel Ruiz de Murga, 1709, $4^{\circ}$.

29. Experiencias de Amor y Fortuna, Madrid 1732

QuintanA, Francisco de, Experiencias de amor, y fortuna, Madrid, Angel Pasqual, $1723,8^{\circ}$.

30. Republica Literaria, Madrid 1759

SAAVEDRA FAJARDO, Diego de, República literaria escrita por Don Diego de Saavedra y Faxardo, en Madrid, dala a luz Doña Angela de Apontes vecina é impressora en esta Corte, $1759,8^{\circ}$.

21 El traductor fue F. Warner o T. Nugent.

22 La traducción es obra de José Francisco de Isla. 
31. Vida del Conde Tekeli, Madrid 1738

La famosa historia del Conde Emerico Tekeli, traducida de la novela histórica que salió en francés año de 1686 y añadida con todos los demás hechos en Ungría... por Don Joseph Rodriguez, Madrid, Manuel Fernandez, 1738, $8^{\circ}$.

\section{I.3. EDICIONES BODONIANAS}

32. Atti della Coronazione di M. M. Morelli Fernandes, impresas por Bodoni, Parma $4^{\circ}$.

Atti della solene Coronazione fatta in Campidoglio della insigne poetessa D.na Maria Maddalena Morelli Fernandez Pistoiese tra gli Arcadi Corilla Olimpica, Parma, Impresso nella Stamperia Reale, 1779, $4^{\circ 23}$.

33. Odi de Anacreonte, Parma 1791

ANAKPEONTOE $\tau \eta \operatorname{lov} \mu \varepsilon \lambda \eta$ praefixo commentario et variant. lect., Parmae, in Aedibus Palatinis, $1791,16^{\circ 24}$.

34. Horatii Opera, exquisitamente encuadernadas en tafilete azul, Parma 1791 fol. Q. Horatii Flacci Opera, Parmae, in aedibus Palatinis typis Bodonianis, 1791, fol.

35. * Q. Horatii Opera, en gran papel, encuadernado a juego con el artículo $n .^{\circ} 39$ e ilustrado con las estampas que se prepararon para el rey de Suecia Gustavo III, Parma 1791 fol.

De esta obra sólo se tiraron 50 ejemplares en gran papel y hace unos tres años el impresor escribió a un amigo suyo de aquí comunicándole que «De Orazio $e$ del Virgilio in Carta sopraffina levigata, non ne rimane piu esemplare vendibili.» $Q$. Horatii Flacci Opera, Parmae, in aedibus Palatinis typis Bodonianis, 1791, fol. ${ }^{25}$

36. Versi del Abate Vicenzo Monti, impresos por Bodoni, Parma

Versi dell'Abate Vincenzo Monti, Parma, dalla Stamperia Reale, 1787, 2 vols., $8^{\circ 26}$.

23 La poetisa italiana Maria Maddalena Morelli Fernández (1727-1800), se casó en Nápoles con el coronel español don Fernando Fernández, gobernador del presidio de Orbetello, del que se separó al poco tiempo. (H. C. BRooKs, Compendiosa Bibliografia di Edicizioni Bodoniane, Firenze, Tipografia Barbèra, 1927, n. ${ }^{\circ}$ 135; a partir de aquí identificaré la impresión bodoniana por el número que le asigna Brooks).

${ }^{24}$ Podría tratarse de la edición en $16^{\circ}$ (Brooks 421) o de la edición en $8^{\circ}$ (Brooks 422). Ambas llevan un retrato de Azara.

${ }_{25}$ Edición costeada por José Nicolás de Azara. El Horacio es el primer volumen producido por la imprenta particular bodoniana, paralela a Stamperia reale parmesana (Brooks 417). La edición del texto estuvo a cargo de Esteban de Arteaga, secretario de Azara, y Ennio Quirino Visconti. La tirada fue de sólo 129 ejemplares. Azara se reservó dos de los cuatro ejemplares impresos en pergamino romano. Asimismo se hizo enviar a Roma media docena en papel avitelado y cuarenta y ocho ejemplares en papel royal. A España envió un ejemplar en papel avitelado, magníficamente encuadernado en tafilete, para regalar al rey y una docena en papel royal para amigos y compromisos entre éstos, Aranda y Floridablanca-.

26 El volumen I está dedicado a la marquesa de Matallana, nacida Lady Conock (Brooks 331). 
37. Prudentii Opera, impresas por Bodoni, 2 vol. Parma $17884^{\circ}$.

Aurelii Prudentii Clementis V. C. Opera omnia nunc primum cum codd. Vaticanis collata praefatione, variantibus, notis, ac rerum verborumque indice locupletissimo aucta et illustrata, Parmae, ex Regio Typographeo, 1788, 2 vols., $4^{027}$.

38. P. Virgilii Maronis Opera, impresas por Bodoni, 2 vol. Parma 1791 fol.

P. Virgilii Maronis Opera, Parmae, in Aedibus Palatinis, 1793, 2 vols., fol.

39. * Publii Virgilii Opera, impresas por Bodoni en gran papel, en que sólo se tiraron 25 ejemplares, magníficamente encuadernadas en tafilete rojo, azul y amarillo, e ilustradas con estampas de la antigüedad, 2 vol. Parma 1793 fol.

P. Virgilii Maronis Opera, Parmae, in Aedibus Palatinis, 1793, 2 vols., fol. ${ }^{28}$

40. P. Virgilii Opera, encuadernadas a juego con el lote 34, Parma 1793 fol.

P. Virgilii Maronis Opera, Parmae, in Aedibus Palatinis, 1793, 2 vols., fol.

II. DICCIONARIOS Y OBRAS DE FILOLOGÍA

\section{II.1. DICCIONARIOS}

41. Diccionario de la Real Academia, Madrid 1783 fol.

Diccionario de la lengua castellana compuesto por la Real Academia española... Segunda edicion, Madrid, por D. Joaquin Ibarra Impressor de Cámara de S.M. y de la Real Academia, 1783, fol.

42. Diccionario y vocabulario, en esp. fr. y cat. Barcelona 1647

LACAVAllería, Pedro, Dictionario castellano... Dictionaire françois... Dictionari catala..., Barcelona, Pere Lacavalleria, $1647,4^{\circ}$.

43. Nomenclature de Lobo, Lond. $17764^{\circ}$.

LoBo, Daniel, A Nomenclature; or Dictionary, in English, French, Spanish, and German, of the principal articles manufactured in this Kingdom; more particularly those in the hardware and cutlery trades; the goods imported and exported, London, 1776, $4^{\circ}$.

44. Diccionario inglés, francés, español y alemán, Lond. $17764^{\circ 29}$.

27 La edición bodoniana de Prudencio (Brooks 361), al cuidado del abate Teoli, de la Biblioteca Apostólica Vaticana, fue la edición favorecida por Azara y su círculo, que vieron la preparada por el jesuita expulso Faustino Arévalo una molesta competidora (Carmina... et lectt. variant. illustr. a Faustino Arevalo, Romae, Apud Antonium Fulgonium, 1788, 2 vols., fol.).

${ }_{28}$ La edición fue costeada por Azara. La corrección del texto estuvo al cuidado del abate Visconti, bibliotecario de la Vaticana y asiduo colaborador de Azara entre 1786 y 1793. La tirada fue de 53 ejemplares (Brooks 486). Azara se reservó dos de los tres que se imprimieron en pergamino romano.

29 Se trata de un duplicado de la obra $n .^{\circ} 45$. 
45. Diccionario de Sejournant, español y francés, 2 vol. Paris $17544^{\circ}$.

Séjournant, Nicolas de, Noveau dictionaire espagnol-françois et latin, composé sur les dictionnaires des académies royales de Madrid et de Paris, par M. de Séjournant..., Paris, C.-A. Jombert, 1759, 2 vols., $4^{\circ}$.

II.2. OBRAS DE FILOLOGÍA

46. Alderete Origen de la Lengua Castellana, Madrid 1674 fol.

ALDRETE, Bernardo, Del origen y principio de la lengua castellana, o Romance que hoy se usa en España..., Madrid, Melchor Sanchez, 1674, fol.

47. Gramática española de Delpino, London 1766

GIRAL DEL PINo, Hipólito San José, A new Spanish grammar; or The Elements of the Spanish language, London, J. Nourse, 1766, $8^{\circ}$.

48. Gramática de la Real Academia, Madrid 1779

Gramática de la lengua Castellana compuesta por la Real Academia Española. Tercera Impresion, Madrid, Por D. Joaquin de Ibarra impresor de Cámara de S.M. y de la Real Academia, 1781, $8^{\circ 30}$.

49. Aelii Antonii Institutiones, impresas por la viuda de Manuel Ibarra, pariente de Joaquín, el Tonson español, Cervera 1757

NEBRIJA, Elio Antonio de, Aelii Antonii Nebrissensis Grammaticarum Institutionum, libri quatuor. Nunc denou ad publicam utilitatem diligentissimê recogniti: nec non Gotholaunicis, Explanationibus, ac Nota illustrati... Opera D. Gerardi Marcillo, Presbyteri Olotens. in Barcinonensi Universitate... Profesoris, Cervariae, Typis Academicis apud Antoniam Viduam Emmanuelis Ibarra, anno 1757, $8^{\circ}$.

50. Ortografia de la Lengua Castellana, Madrid 1779

Ortografía de la Lengua Castellana, compuesta por la Real Academia Española. Sexta impresion, corregida y aumentada, Madrid, por D. Joaquin Ibarra impresor de Cámara de S.M. y de dicha Real Academia, 1779, $8^{\circ 31}$.

51. Oudin Refranes Castellanos, en español y francés, Paris 1624

OudiN, Cesar, Refranes o proverbios castellanos traducidos en lengua francesa. Proverbes espagnols traduits en françois, par..., Paris, P. Billaine, 1624, $8^{\circ}$.

30 Adquirido a Steuart por la Faculty of Advocates de Edimburgo y hoy conservado en la National Library of Scotland (signatura may=k.109.f). En la contraportada todavía conserva el exlibris en papel de Stuart y la inscripción manuscrita «Ex libris Bibliothecae Facultatis Juridicae Edinburgi. 1801». Con encuadernación original en pergamino.

${ }_{31}$ Comprado a Steuart por la Faculty of Advocates de Edimburgo y hoy presente en la National Library of Scotland (signatura [AG].7/1). En la contraportada todavía conserva el exlibris en papel de Stuart y la inscripción manuscrita «Ex libris Bibliothecae Facultatis Juridicae Edinburgi. 1801». Con encuadernación original en pergamino. 
52. Refranys Valencians, Valencia 1736

Ros, Carlos, Tratat de adages, y refranys valencians, y practica pera escriure ab perfecció la lengua valenciana. Escrit per Carlos Ros... Segona impressió, En Valencia, en la Imprenta de Josep Garcia, any $1736,8^{\circ}$.

\section{BELLAS ARTES}

53. Lives of Spanish Painters de Velasco, Lond. 1739

PALOMINO DE CASTRO Y VelASCO, Antonio, An account of the lives and works of the most eminent Spanish painters, sculptors and architects; and where their several performances are to be seen. Translated from the Museum pictórico of Palomino Velasco, London, printed for S. Harding, 1739, $8^{\circ}$.

54. Viage de Espana, por $\mathrm{D}^{\mathrm{n}} \mathrm{Ant}^{\mathrm{o}}$ Pons, con estampas, 8 vol. Madrid 1766

PONZ Y PIQUER, Antonio, Viage de España, o Cartas en que se da noticia de las cosas más apreciables y dignas de saberse que hay en ella... Segunda edición corregida y aumentada, Madrid, Por D. Joachin Ibarra, 1776-1788, 13 vols, $8^{\circ}$.

55. Descripcion de el Escorial, Madrid 1698 fol.

Santos, Fray Francisco de los, Descripcion del Real Monasterio de San Lorenzo de El Escorial. Unica maravilla del Mundo..., en Madrid, en la Imprenta de Juan Garcia Infançon impressor de la Santa Cruzada, 1698, fol.

IV. RELIGIÓN, PENSAMIENTO Y EDUCACIÓN

\section{IV.1. RELIGIÓN CATÓLICA}

56. Font Mistica y Sagrada, Figueras $17604^{\circ}$.

BAUCELls, Francesc, Font mistica y sagrada..., Figueras, En la Estampa de Ignaci Porter, $1760,4^{\circ}$.

57. Gracias de la Gracia, Barcelona

BONETA y LAPLANA, Joseph, Gracias de la Gracia. Saladas agudezas de los Santos. Insinuacion de algunas de sus virtudes..., Barcelona, ¿en la Imp. de Rafael Figueró, 1719 o Nadal, 1748?, $8^{\circ}$.

58. L'Opere Spirituale del Duca di Gandia, Venecia 1561

FRANCISCO DE BORJA, Tutte l'opere spirituali... divise in VIII tratatti, e tradotte dal loro volgar Castigliano, per... Vincenzo Buondi... con una epist. di S. Bernardo della perfettione della vita Christiana tradotta del medesimo, Vinegia, Gabriel Giolito de'Ferrari, $1561,8^{\circ}$.

59. La Vida de Santa Magdalena de Cobblés, Valencia $15054^{\circ}$. Ésta es una de las muestras más singulares de la antigua tipografía ${ }^{32}$.

32 El ejemplar de esta obra que pasó por las manos del librero anticuario Vicente Salvá (Catálogo de la Biblioteca de Salvá, 630), fue el que anteriormente había perte- 
Gazull, Jaume, La vida de santa Magdalena en Cobbles, Estampada en la insigne ciutat de Valencia, per ioan iofre, acabada a XV de mars Any md e cinch [1505], $4^{\circ}$.

60. Guia de Pecadores, por Fr. Luis de Granada, Salamanca 1572

GranAda, Luis de, Guia de pecadores..., En Salamanca, En casa de Andrea de Portonaris, $1572,8^{\circ}$.

61. Granada del Symbolo de la Fe, Salamanca 1585 fol.

El estilo de este autor es un modelo de lengua española.

GRANADA, Luis de, Introduction del Symbolo de la Fe..., En Salamanca, por los herederos de M. Gast, 1585, fol.

62. Kempis de la Imitació de Christo, Gerona 1759

La portada promete 320 días de remisión de las penas del purgatorio a todo aquel que lea o escuche hasta el final un capítulo de este libro.

KeMPIS, Thomas de, De la imitació de Christo, Gerona, Per Joseph Bró Estamper, $12^{\circ}$.

63. Flos Sanctorum Barcelona 1760 fol. ${ }^{33}$

64. Joyell Precios, Barcelona 1714

Este libro ha pasado por las manos de la Inquisición, como manifiesta el certificado del calificador, que ha tachado muchos pasajes.

Sapera, Vicente, Joyell preciós y adorno de la ánima devota, que vol perfectament agradar a Déu. Conté la Regla, Ordinacions, Exercicis, Grácies e Indulgències de la Venerable Tercera Orde de Penitencia de N.P.S. Francesch, Barcelona, Joseph Llopis, $1714,24^{\circ}$.

65. Tresor pera als viusy Almoyner del Purgatori, Olos.

Tresor per als vius y almoyner del Purgatori lo Rosari de Maria Santissima Traduit en cathalá per M. R. Jaume Roca Prevere. Y en esta impressio... se ha traduit lo Llati en cathalá, Vich, Per Joan Dorca estamper, [s.a., pero siglo XVIII], $8^{\circ}$.

\section{IV.2. JUDAÍSMO}

66. Tratado del Temor Divino Amst. 1693

COHEN DE LARA, David Ben Izchael, Tratado del Temor Divino, extracto del doctissimo libro llamado Ressit hohmá. Traduzido nuevamente del hebrayco, a

necido a Thomas Crofts, apareciendo descrito en el catálogo de venta de su biblioteca (Catalogue of the curious and distinguished library of the late Reverend and Learned Thomas Crofts, London, $1783,8^{\circ}$ ). Salvá la considera obra rarísima, ponderando la profusión y riqueza de sus estampas. Es muy posible que el ejemplar que poseyó Steuart procediese de Crofts.

33 No hemos localizado ninguna edición barcelonesa de 1760 de esta obra de Pedro de Ribadeneyra. Quizá podría tratarse de la edición Flos Sanctorum de las Vidas de los Santos, escrito por el Padre Pedro de Ribadeneyra..., Barcelona, Imprenta de Teresa Piferrer viuda por Thomas Piferrer librero, 1751, 3 vols., fol. 
nuestro vulgar idioma por Daniel hijo de Ishac Cohen de Lara, En Amsterdam, En casa de Menasseh C.J.C. Israel, 5393 [1633], $4^{\circ}$.

67. Poemas de Mendez, Lond.

Mendez, Moses, A Collection of the most esteemed pieces of Poetry... with variety of originals by the late M. Mendez, 1767, $8^{\circ}$.

68. Orden de los cinco Tahaniot, Amst. $1708^{34}$.

69. Orden di los cinco Tahaniot, encuadernado en piel de pescado, con broches, Amst $^{35}$.

70. Orden de Ros Asanah y Kypur, Amst ${ }^{36}$.

71. Orden de Ros Asanah y Kypur ${ }^{37}$.

72. Tratado de la Confiança em Deus, Amst. $17304^{038}$.

73. Certamen Penitentiale, Amst. 1733

Valle Saldaña, David, 'Certamen penitentiale. Batalla penitente, Amsterdam, $1733,8^{\circ}$

34 Edición sin identificar. Obra a subastar en la segunda jornada de la venta, es decir, el martes 19 de mayo de 1801. Colocada entre las de formato octavo o inferior.

${ }^{35}$ Edición sin identificar. Obra a subastar en la tercera jornada de la venta, el miércoles 20 de mayo de 1801. Colocada entre las de formato octavo o inferior. Podría tratarse de una de las ediciones de esta obra que se imprimieron en Amsterdam en 1648 o 1660. Por lo que respecta a su encuadernación, se alude a la piel con grano conocida como chagrín o zapa - denominación presente ya en el Diccionario de Autoridades-, fabricada a partir de la piel de la espalda del caballo y utilizada en los siglos XVII y XVIII en la fabricación de cajas especialmente cuidadas o para coberturas de objetos de lujo - como, por ejemplo, fundas de espada de oficiales-. El chagrín también se hacía con piel de tiburón y raya. La Compañía holandesa del Este de la India importaba a Europa piel de raya a mediados del siglo XVII. En Amsterdam, durante el siglo XVIII, también se comercia con pieles de tiburón traídas de Francia, concretamente de Bayona y Normandía. Entre 1720 y 1800 el chagrín se utiliza en Inglaterra para cubrir secciones de instrumentos científicos, tales como microscopios y catalejos. Se suele teñir de verde, rojo o morado. En Inglaterra en la segunda mitad del siglo XVIII, los fabricantes de cajitas de zapa utilizan la denominación «dogskin» para la piel de tiburón y «fishskin» para la piel de la raya. Vid. M. Willemsen, "Shagreen in Western Europe. Its use and manufacture in the seventeenth and eighteenth centuries», Apollo January 1997, pp. 35-38.

36 Edición sin identificar. A subastar en la sexta jornada de la venta, el sábado 23 de mayo de 1801. En el catálogo de venta se incluye entre las de formato octavo o inferior. A lo largo de los siglos XVII y XVIII se imprimió esta obra en Amsterdam al menos en los siguientes años: 1630, 1652, 1663, 1648, 1693, 1695, 1706, 1717 y 1726.

37 Edición sin identificar. Obra a subastar en la segunda jornada, a tener lugar el martes 19 de mayo de 1801. Según el catálogo de venta, su formato es octavo o inferior.

38 No hemos logrado identificarla. Posiblemente sea obra de un judío portugués. Situada en el catálogo entre las obras de formato cuarto a subastar en el sexto día de la venta — sábado 23 de mayo de 1801-. 


\section{IV.3. PROTESTANTISMO}

74. Liturgia Inglesa Lond.

La Liturgia Ynglesa, ó el Libro de la Oracion Commun... Hispanizado por D. Felix Anthony de Alvarado, Londres, G. Bowyer. A costa de Fran. Coggan, $1707,8^{\circ 39}$.

75. Idem por $\mathrm{D}^{\mathrm{n}}$ Felix de Alvarado, Lond. 1785

La Liturgia Ynglesa, o el Libro de la Oracion Comun... hispanizado por D. Felix de Alvarado. Edicion segunda corregida y augmentada, Londres, William Bowyer, $1715,8^{\circ}$.

76. La Apologia de Barclay, en español, Lond. 1710

BARClAy, Robert, Apologia de la Verdadera Theologia Christiana, como ella es professada, y predicada, por el pueblo llamado en menosprecio los Tembladores... escrita en Latin é Ingles... trasladada...' en Castellano por Antonio de Alvarado, originario de Sevilla, por el bien de todos, especialmente de la nacion española, en Londres, por J. Sowle, 1710, $8^{\circ}$.

77. Biblia Sacra de Cassiodoro de la Reyna -véase De Bure, $n^{\circ} 73$ - Berne $1569,4^{\circ}$. La Biblia, que es los sacros libros del vieio y nuevo Testamento. Trasladada en Español, $1569,4^{\circ} 40$.

78. La edición pirata de la obra anterior $4^{\circ}$.

La Biblia, que es los sacros libros del vieio y nuevo Testamento. Trasladada en Español, En la libreria de Daniel y David Aubrii y de Clement Schleich, 1622, $4^{\circ}$.

39 El sevillano Félix Antonio de Alvarado, refugiado en Londres a comienzos del siglo XVIII, fue ministro de la iglesia anglicana y capellán de los ingleses comerciantes con España. En 1718 publicó unos Dialogos ingléses y españoles. Con muchos proverbios, y las explicaciones de divérsas maneras de hablar (Londres, a costa de Guillermo Hinchliffe, $1718,8^{\circ}$ ), que dedicó a lord Carteret. De La Liturgia Ynglesa -anglicana- se hicieron ediciones en 1707 y 1715. La Apologia de la Verdadera Theologia Christiana es una exposición de los principios y doctrinas de los cuáqueros, iglesia de las entonces consideradas disidentes en Inglaterra. Según Menéndez Pelayo, fue la lectura de este libro, en esta edición, la que convirtió al cuaquerismo a Luis Usoz y Río. Vid. M. MENÉNDEZ PELAYO, Historia de los heterodoxos españoles (por la edición Madrid, Biblioteca de Autores Cristianos, 1987, en II, pp. 400-403 y 901).

40 Escribe De Bure: «Cette Bible, qui est Calviniste, a été mise au jour par Cassiodore Reyna, dont le nom se trouve désigné par ces deux lettres C. R. que l'on remarque à la fin de la Préface qui est latine... Elle est connue de quelques personnes, sous le nom de Bible de l'Ours, à cause de la représentation de cet animal, que l'on trouve gravé dans le fleuron du Frontispice... L'édition que nous annonçons ici, de l'année 1569, est l'originale: elle n'est point commune, \& on la préfere à cettes qui ont suivi parce que ces dernieres passent pour avoir été mutilées.» (Guillaume-François De Bure, Bibliographie instructive ou Traité de la connoissance des livres rares et singuliers. Volume de Théologie, Paris, Chez Guillaume-François De Bure le Jeune, 1763, pp. 9899). La bibliografía de G. F. De Bure (1731-1782), es la verdadera biblia del bibliófilo de la segunda mitad del siglo XVIII y primeros años del XIX. 
79. Institucion de la Religion Christiana, por Juan Calvino, 1597 fol.

Calvin, Jean, Institucion de la Religion Christiana compuesta en quatro libros... traduzida en Romance Castellano, por Cypriano de Valera, En casa de Ricardo del Campo [Richard Field], [Londres], 1597, $4^{\circ}$.

80. Catholico Reformado, Amst. 1624

William Perkins, Catholico reformado, En Amsterdam, En casa de Iacob Wachter, $1624,24^{\circ} 4$.

\section{IV.5. PENSAMIENTO}

81. Abarbanel Dialogos de Amor, Venice $15684^{\circ}$.

ABARBANEL, León, Los Diálogos de amor, En Venetia, Con Lizenza dell Superiori, $1568,4^{\circ}$.

82. Vida y Hechos de Varones Griegos y Romanos, Antwerp 1549

ERASMO, Desiderio, Libro de vidas, y dichos graciosos, agudos y sentenciosos, de muchos notables varones Griegos y Romanos, ansi reyes y capitanes, como philosophos, $y$ oradores antiguos: en los quales se contienen graves sentencias $e$ avisos no menos provechosos que deleytables. Añadiose la tabla de Cebetes philosopho, en la qual se representa toda la vida humana, para incitar los animos al uso de las virtudes, Anvers, en casa de Juan Steelsio, 1549, $8^{\circ}$.

83. Feijoo Cartas Eruditas, 5 vol. Madrid $17654^{\circ}$.

FeiJoo y Montenegro, Fray Benito Jerónimo, Cartas eruditas, y curiosas... Nueva impresión. Con las licencias necesarias, Madrid, Gabriel Ramírez, 1765, 5 vols., $8^{\circ} \mathrm{m}$.

84. Feijoo Cartas Apologeticas, Madrid $17654^{\circ}$.

FEIJOO y MONTENEGRo, Fray Benito Jerónimo, Ilustración apologética..., Madrid, Antonio Sanz. A costa de la Compañía de Impresores y Libreros del Reyno, 1765, $8^{\circ} \mathrm{m}$.

85. Feijoo Theatro Critico, 8 vol. Madrid $17694^{\circ}$.

Feijoo y Montenegro, Fray Benito Jerónimo, Teatro Crítico Universal, o Discursos varios en todo género de materias, para desengaño de errores comunes... Nueva impresión, Madrid, Joachin Ibarra, 1769, 8 vols., $8^{\circ} \mathrm{m}$.

86. El Heroe de Lorenzo Gracian, Amst. 1659

GraCIÁN, Baltasar, El Heroe de Lorenzo Gracian Infanzón. En esta impression nuevamente corregido, A Amsterdam, En casa de Juan Blau, 1659, $12^{\circ}$.

87. Guevara Epistolas Familiares, Antwerp 1665

GuEvara, Antonio de, Epistolas familiares de... predicador, Chronista, y del Consejo del Imperador Don Carlos, Anveres, En Casa de Jacobo Meurcio, 1665, 2 vols., $8^{\circ}$.

41 La traducción fue obra de Cipriano de Valera. 
88. Examen de Ingenios, muy raro, Granada 1768

HUARTE DE SAN JUAN, Juan, Examen de ingenios para las ciencias, Granada, Imprenta Real, [1768], $8^{\circ}$.

IV.6. EDUCACIÓN

89. Instruccions per los Minyons, Gerona

Rexach, Baldiri, Instruccions per la ensenyansa de Minyons Escritas per lo Reverent Baldiri Rexach, Prevere, y Rector de la Iglesia Parroquial de Sant Martí de Olles, Bisbat de Gerona. Obra utilissima per la instruciò dels Minyòns y descàns dels Mestres, ab Laminas Finas pera apendrer be de escriurer, Gerona, Per Narcis Oliva Estampér y Llibreter à la Plasa de las Cols, [1748], $8^{\circ}$.

\section{HISTORIA}

90. Agostini Dialoghi intorno alle Medaglie, Rome fol.

AGUSTín, Antonio, Dialoghi intorno alle medaglie, inscrittioni et altre antichità; tradotti... de Dionigi Ottaviano Sada, Roma, G. Faciotto, 1592, fol.

91. Ant $^{\circ}$ Agostini delle Medaglie, con estampas, Rome 1650 fol.

Agustín, Antonio, Dialogui delle Medaglie... Tradotti... de Dionigi Ottaviano Sada..., In Roma, Apresso Filippo de Rossi, 1650, fol.

92. Augustin Dialogos de Medallas, con estampas, Madrid, $17444^{\circ}$.

Agustín, Antonio, Dialogos de Medallas, Inscripciones, y otras antiguedades, Madrid, En la Oficina de Joseph Martinez Abad, 1744, $4^{\circ}$.

93. Argensola, Conquista de las Molucas, primera edición, Madrid, 1609 fol.

LeOnardo DE ARgensola, Bartolomé, Conquista de las Islas Malucas Al Rey Felipe III... Escrita por el Licenciado..., En Madrid, Por Alonso Martin, año 1609, fol. ${ }^{42}$

94. Commentarios de la Guerra de Espana, 2 vol. $4^{\circ}$.

BACAllaR y SANNA, Vicente, marqués de San Felipe, Comentarios a la guerra de España, e historia de su Rey Phelipe V el Animoso, desde el principio de su reinado hasta el año 1725..., Genova, Matheo Garvizza, 1725, 2 vols., $4^{\circ}$.

95. Commentarios de la Guerra de Espana del Marques de San Phelipe, 2 vol. Genoa $4^{\circ}$.

BACAllar y SANNA, Vicente, marqués de San Felipe, Comentarios a la guerra de España, e historia de su Rey Phelipe V el Animoso, desde el principio de su reinado hasta el año 1725..., Genova, Matheo Garvizza, 1725, 2 vols., $4^{\circ}$.

42 Comprado a Steuart por la Faculty of Advocates de Edimburgo y hoy presente en la National Library of Scotland (signatura A.74.b.1). En su contraportada lleva la inscripción manuscrita «Ex libris Bibliothecae Facultatis Juridicae Edinburgi. 1801». 
96. Discurso sobre la Historia Universal, 3 vol. Lyons 1751

BosSUET, Jacques-Bénigne, Discursos sobre la historia universal... por el illustrissimo Jayme Benigno Bossuet... nuevamente traducidos del frances en lengua española..., En Leon de Francia, por. J. Certe, 1751, 3 vols., $8^{\circ}$.

97. Capmany Memorias Historicas de Barcelona, 2 vol. Madrid $17794^{\circ}$.

Capmany Y MonTPalaU, Antonio de, Memorias históricas sobre la Marina, Comercio y Artes de la ciudad de Barcelona. Publicadas... y dispuestas por Don..., Madrid, En la Imprenta de D. Antonio de Sancha, 1779-1792, 4 vols., $4^{\circ}$.

98. Las Casas Relacion de la Destruccion de las Indias y otras obras suyas, $15524^{\circ}$. En los últimos cincuenta años sólo ha salido en venta un ejemplar de esta obra. Casas, Bartolomé de las, Brevissima relacion de la destruycion de las Indias, Sevilla, en casa de Sebastian Trugillo, $1552,4^{\circ}$.

99. Las Casas Account of the Spaniards in America, Lond. 1699

CASAS, Bartolomé de las, An Account of the First Voyages and Discoveries Made by Spaniards in America, London, for D. Brown Darby, 1699, $8^{\circ}$.

100. Comentarios de Julio Caesar, por Toledo, Madrid 1621

CÉSAR, Cayo Julio, Los Comentarios de Gayo Julio Cesar... Traduzidos en castellano por Frey Diego Lopez de Toledo, En Madrid, por la Viuda de Alonso Martin, $1621,4^{\circ}$.

101. Charlevoix Histoire du Paraguay, 3 vol. Paris $17564^{\circ}$.

CharlevolX, Pierre-François-Xavier de, Histoire du Paraguay, par le R. P. PierreFrançois-Xavier de Charlevoix..., Paris, Didot, 1756, 3 vols., $4^{\circ}$.

102. De Insulis nuper Inventis Fernandi Cortes, 1532 fol.

CORTÉs, Hernán, De Insulis nuper Inventis Ferdinandi Cortesii ad Carolum V Rom. Imperatores Narrationes..., Coloniae, ex officina Melchioris Novesiani Impensis Arnoldi Birkman, Anno 1532, fol.

103. Bernal Diaz del Castillo Historia de la Conquista de la Nueva España, primera edición de esta rara y valiosa obra, Madrid 1632 fol.

DíAZ DEL CASTILlo, Bernal, Historia verdadera de la Conquista de la Nueva España. Escrita por el capitan..., Madrid, en la Imprenta del Reyno, Año de 1632, fol.

104. Guerras de Flandes, par el P. Estrado, 3 vol. Antwerp 1701

Estrada, Famiano, Primera decada de las guerras de Flandes desde la Muerte del Emperador Carlos V hasta el Principio del Govierno de Alexandro Farnese... escrita en latin por el R. P. Famiano Estrada..., Amberes, Por Henrico, y Cornelio Verdussen, $17+01,3$ vols., $8^{\circ}$.

105. Historia de $\mathrm{D}^{\mathrm{n}}$ Juan de Austria, Zaragoça $16734^{\circ}$.

FABRO BREMUNDAN, Francisco, Historia de los hechos del serenissimo señor Don Juan de Austria, en el Principado de Cataluña. Parte I, Caragoça, emprenta de Diego Dormer, 1673, fol. 
106. Grandezas de Madrid, par Gil Gonzalez de Avila, Madrid $16234^{\circ}$.

GonZÁlez DE AvilA, Gil, Teatro de las grandezas de la villa de Madrid Corte de los Reyes Catolicos de España. Por el maestro Gil Gonçalez Davila..., Madrid, Tomas Junti, 1623, fol.

107. Historiadores Primitivos, 3 vol. Madrid 1749 fol.

GoNZÁlEZ DE BARCIA CARBAllido Y ZÚÑIGA, Andrés, Historiadores primitivos de las Indias Occidentales, que juntó, traduxo en parte, y sacó á luz, ilustrados con eruditas notas, y copiosos indices... divididos en tres tomos, Madrid, 1749, fol.

108. Abregé de l'Histoire d'Espagne et de Portugal, 2 vol. Paris $1765^{43}$.

HENAULT, Charles, Abregé chronologique de l'histoire d'Espagne et de Portugal, Paris, 1765, 2 vols., $8^{\circ}$.

109. Herrera Historia, 8 tom., encuadernados en cuatro vols., Madrid 1601 fol.

HerRera TORDESILlas, Antonio de, Historia general de los hechos de los Castellanos en las Islas $i$ Tierra firme del Mar Oceano, escrita por..., En Madrid, [Décadas I-IV:] Emprenta Real, por Juan Flamenco; [Décadas V-VIII:] Juan de la Cuesta, 1601-1615, 8 partes en 4 vols., fol.

110. Mendoza Guerra de Granada por el Rey $D^{n}$ Phelipe $2^{\text {ndo }}$, Madrid $16744^{\circ}$.

Hurtado DE MEndoza, Diego, Guerra de Granada, Madrid, Imprenta Real, $1674,4^{\circ}$.

111. Isla Compendio de la Histoire de Espana, 2 vol. Madrid 1764

IsLA, José Francisco de, Compendio de la Historia de España escrito en francés por el $R$. P. Duchesne, de la Compañía de Jesús... con algunas notas críticas que pueden servir de Suplemento, por el mismo Traductor, Madrid, Joachin Ibarra, 1764,2 vols.

112. Garcilaso de la Vega Commentaries of Peru, Lond. 1688 fol.

LASO DE LA VEGA, Garci, The Royal Commentaries of Peru, in two parts. The First Part treating of the original of their Incas... With many other particulars relating to their empire and policies before such time as the Spaniards invaded their countries. The Second Part describing the manner by which that new World was conquered by the Spaniards... Rendred into English by Sir P. Rycaut, London, M. Flesher for C. Wilkinson, 1688, fol.

113. Tito Livio Traduzido en Espanol, Antwerp fol.

Livio, Tito, Todas las decadas de Tito Livio paduano, que hasta el presente se hallaron y fueron impresas en latin, Anvers, ¿Arnoldo Byrcman o Pedro Belero?, ¿1552 o 1553?, fol.

43 El ejemplar de Steuart se conserva en la National Library of Scotland, signatura 5.192.h. 
114. Historia di $\mathrm{D}^{\mathrm{n}}$ Fernando Cortes, Venice 1560

LÓPEZ DE GÓMARA, Francisco, Historia del... Capitano Don Ferdinando Cortes, Venetia, Francesco Lorenzini da Trino, 1560, $12^{\circ}$.

115. Gomara Historia de Mexico, Antwerp 1554

LóPEZ DE GoMARA, Francisco, Historia de Mexico, Anvers, por Juan Lacio, $1554,8^{\circ}$.

116. Alcaide Abulcacim Tarif Abentarique Historia Verdadera del Rey $\mathrm{D}^{\mathrm{n}}$ Rodrigo, $M a$ drid $16544^{\circ}$.

LUNA, Miguel de, Historia verdadera del rey Don Rodrigo... compuesta por el sabio alcayde Abulcacim Tarif Abentarique... nuevamente traducida de la lengua arabe por Miguel de Luna..., En Madrid, por M. Sanchez, 1654, $4^{\circ}$.

117. Mariana Historia de Espana, 2 vol. Madrid 1635 fol.

MARIANA, Juan de, Historia, general de España, Madrid, Francisco Martínez, 1635, 2 vols., fol.

118. Reflexiones Imparciales sobre la humanidad de los Espanoles en las Indias contra los pretendidos Philosophos y Politicos, para ilustrar las Historias de Monsures Raynal y Robertson, Madrid $4^{\circ}$.

NUIX, Juan, Reflexiones imparciales sobre la humanidad de los españoles en las Indias contra los pretendidos filósofos y políticos. Para ilustrar las historias de MM. Raynal y Robertson. Escritas en italiano... y traducidas con algunas notas por D. Pedro Varela y Ulloa, Madrid, Por D. Joachin Ibarra Impressor de Cámara de S.M., $1782,4^{\circ}$.

119. Guerras de Granada, por G. P. de Hita, Barcel. 1757

PÉREZ DE HITA, Ginés, Historia de los Vandos de los Zegries y Abencerrages, Cavalleros Moros de Granada y las Civiles Guerras que huvo en ellas, hasta que el Rey Don Fernando el Quinto la ganó, traducia al Castellano por..., Barcelona, Lucas de Bezares, $1757,8^{\circ}$.

120. Raynal Histoire Philosophique \& des Indes, 10 vol. Geneva 1783

RAYNAL, Guillaume-Thomas-François, Histoire philosophique et politique des établissemens et du commerce des Européens dans les deux Indes, par..., Genève, 1783,10 vols., $8^{\circ}$.

121. Ribera Noticia de la Gran Bretana, Madrid $17674^{\circ}$.

RIBERA, Nicolás de, Noticia de la Gran Bretaña, con relación a su estado antiguo y presente: escrita en inglés por Juan Chamberlain, y traducida al castellano por Don..., Madrid, Joachin Ibarra, 1767.

122. Histoire de Charles V. par Robertson, elegantemente encuadernado en tafilete rojo, Amst. $17714^{\circ}$.

ROBERTSON, William, L'Histoire du règne de l'empereur Charles-Quint, précédé d'un tableau des progrès de la société en Europe... par M. Robertson... ouvrage traduit de l'anglois, Amsterdam et Paris, Saillant et Noyer, 1771, 2 vols., $4^{\circ}$. 
123. Vida del Cardenal Dn Fray Francisco Ximenez de Cisneros, con el escudo de armas en portada y colofón, Toledo $16044^{\circ}$.

Véase De Bure, $n^{\circ} 4442$, para una referencia de esta rarísima obra ${ }^{44}$.

ROBLES, Eugenio de, Compendio de la vida y hazañas del cardenal don fray Francisco Ximenez de Cisneros y del oficio y missa muzarabe por..., Toledo, $\mathrm{P}$. Rodriguez, $1604,4^{\circ}$.

124. Historia de la Conquista de Mexico, por $\mathrm{D}^{\mathrm{n}}$ Antonio de Solis, primera edición -Véase De Bure, $n^{\circ}$ 5645-Madrid 1684 fol.

Solís, Antonio de, Historia de la conquista de Mexico, poblacion, y progressos de la America septentrional, conocida por el nombre de Nueva España. Escriviala..., Madrid, Bernardo de Villa-Diego, 1684, fol.

125. Annales de Flandes, 2 vol. Antwerp 1624 fol.

SUEIRO, Emanuel, Anales de Flandes por..., Anvers, En casa de Pedro y Juan Beleros, 1624, 2 vols., fol.

\section{ECONOMÍA Y POLÍTICA}

126. Correspondencia de la Moneda de Castilla a la de Cathaluna con una Tarifa de la Correspondencia de las Monedas de Castilla con las demas partes de Europa, Barcelona

Correspondencia de la Moneda de Cataluña a la de Castilla, y la de Castilla a la de Cataluña, Barcelona, Por Thomas Piferrer impresor del Rey N.S., 1765, $12^{\circ}$.

127. Orazione Funebre in lode di $\mathrm{D}^{\mathrm{n}}$ Carlo $3^{20}$, magníficamente impresa por Bodoni en papel de Annonay, con espléndidas viñetas, Parma $4^{\circ}$.

Orazione funebre in lode di Don Carlo III Re delle Spagne e dell'Indie recitata nella Chiesa de' RR. PP. Cappuccini il dì 8 Gennaio 1789 in occasione delle solenni esequie fatte celebrare dal Real Infante di Spagna Don Ferdinando I Duca di Parma, Piacenza, Guastalla, ec. ec. ec. dall'Abate D. Bernardino Botteri Proposto dell'insigne Collegiata del Battistero di Parma, Parma, dalla Reale Stamperia, s.a. [pero 1789], $4^{\circ 45}$.

128. Orazione Funebre in Morti di Carlo $3^{20}$, Parma $17934^{\circ}$

Orazione funebre in morte di Carlo III Monarca delle Spagne ec. ec. ec. dalla lingua spagnuola nell'italiana con libera traduzione recata, [Parma], [Bodoni], [1789], $4^{046}$.

44 Esta obra contiene una reimpresión de la Breve Suma y Relacion del Officio Gothico Mozarabe en la Capilla de Toledo (Toledo, por Eugenio de Robles, 1603, $4^{\circ}$ )

45 El título indicado por el catálogo de venta, en italiano, parece hacer referencia a la función fúnebre que tuvo lugar en Parma (Brooks 377) y no a la organizada por el Vaticano, cuya oración compuso en latín monseñor Bernardino Ridolfi, ilustrada por Morghen y Volpato (Brooks 384). El papel fabricado en Annonay tenía una calidad avitelada que le hacía muy apetecible.

46 Traducción al italiano por Francesco Milizia del texto castellano compuesto por José Nicolás de Azara (Brooks 381). 
129. Relazione del Solenni Ricevimento di $\mathrm{D}^{\mathrm{n}}$ Carlo, $3^{\mathrm{zo}}$, Parma $17864^{\circ}$. Bellamente impresa por Bodoni.

Relazione del solenne Ricevimento negli Ordini di San Michele e dello Spirito Santo di S.A.R. il Principe Ereditario di Parma Don Lodovico di Borbone, Parma, dalla Stamperia Reale, $1786,4^{\circ}$.

130. Rome, Paris, et Madrid, ridiculés, Paris 1713

Blainville, Rome, Paris et Madrid ridiculés. Avec des remarques historiques et un recueil de poésies choisies, par $M$. de $B^{* * *}$, Paris, P. Le Grand, 1713, $12^{\circ}$.

131. Papeles españoles $4^{\circ}$., a saber:

Moxiganga de Moxigangas ${ }^{48}$

El Patan de Caramanchel ${ }^{49}$

Progressos del Cielo en Defensa de la Religion ${ }^{50}$

La Entrada de $D^{\text {n }}$ Felipe $4^{\text {to } 51}$

Carta Christiana ${ }^{52}$

Carta Segunda ${ }^{53}$

Egloga Narrativa de la Eleccion de Felipe $5^{\text {to }}$

Un Portero del Rey

El Pastor Passado ${ }^{54}$

Xacara en Metoforas del Pecado di Adan y Eva ${ }^{55}$

47 No nos hallamos aquí ante una oración fúnebre a la muerte de Carlos III, sucedida el 14 de diciembre de 1788, sino ante una obra de circunstancia del año 1786, cuyo motivo fue el ingreso del heredero del ducado parmesano, el infante don Luis de Borbón, en la órdenes de San Miguel y del Espíritu Santo (Brooks 316).

48 Mogiganga de mogigangas... sueño fantastico, historico, prognostico, y juridico, Lisboa, à costa de Don Pedro, que es quien lo ha de pagar todo [pero Madrid, s.i., 1707], $4^{\circ}$.

${ }_{49}$ El Patán de Caramanchel despierta, que estaba dormido, a los gritos de tantos papelones, y como poeta antiguo mete también su cucharada, en sus frases, contradiziendo a todos en este Romance. Año 1701, [Madrid, Vicente Almendariz, s.a.], 11 pp., $4^{\circ}$.

${ }_{50}$ Progresos del Cielo, en defensa de la Religion Catolica, contra los Hereges, y en favor de sus Magestades, Católica, y Christianisima, protegidos de Nuestra Señora Maria Inmaculada. Romance Endecasilavo, [s.l., s.i., s.a.], 8 hs., $4^{\circ}$.

${ }_{51}$ Academia de Valencia. En celebracion de la gloriosa entrada en los dominios de España y feliz cumplimiento de años del Rey nuestro Señor Don Felipe IV de Aragon, y $V$ de Castilla. Executada en la casa de la Diputacion del Reyno de Valencia, el dia 2 de Febrero 1704, Valencia, Vicente Cabrera, 1704, 94 pp., $4^{\circ}$.

52 Carta christiana que el piadoso discurso del Dr. Santa Cruz presume haber escrito el Christianissimo Rey de Francia Luis XIV a nuestro Catholico Monarca D. Phelipe $V$, Sevilla, por Francisco Garay, 4 hs., $4^{\circ}$.

${ }_{53}$ Carta segunda, en que continúa Luis Pérez el gallego, al amigo ausente, lo que va sucediendo en las felicidades de nuestro Cathólico Monarca Don Felipe Quinto (que el Cielo prospere) triunfante de sus enemigos, siguiendo su expressión en el empeçado idioma Títulos de Comedias. Redondillas, [Sevilla, Francisco de Leefdael, 1704], 2 hs, $4^{\circ}$.

${ }^{54}$ El Pastor passado cumpliendo con su promessa descifra el exercicio de Pastor hablando con nuestro Rey Felipo Quinto, s.1., s.i., s.a., 8 pp., $4^{\circ}$.

${ }_{55}$ Xacara en metáforas del pecado de Adán y Eva, s.l., s.a. 
Despedimiento que hizó el Marques de Salmeron ${ }^{56}$

Coloquio que tuvieron un Poeta, un Soldado, un Ciego, y un Sordo ${ }^{57}$

Embidioso un Soldado Viscayano ${ }^{58}$

Coloquio Alegorico ${ }^{59}$

Coloquio que tuvieron Montesinos, Gayferos, y Beltenebros ${ }^{60}$

Donayres de Perico y Marica ${ }^{61}$

Coplas para Ciegos ${ }^{62}$

Discurso del Doctor Panarra

El buen Cazador ${ }^{63}$

Coloquio de la Verdad ${ }^{64}$

Perico y Aneta ${ }^{65}$

Aplausos Christianos ${ }^{66}$

Decreto de Su Magestad

Breve de $\mathrm{N}^{\text {ro }}$ muy $\mathrm{S}^{\text {to }} \mathrm{P}^{\mathrm{re}}$ Clemente $11^{\text {mo }}$

Alma del Manifiesto del Elector de Bavaria ${ }^{67}$

56 [Alvarez de Toledo, Gabriel, Romance del despedimiento que el leal afecto del Marqués de Salmerón discurre avrá hecho el Christianissimo Luys el Grande, de nuestro Católico Monarca Felipe Quinto (que Dios guarde), [Barcelona, Francisco Guasch 1701], 2 hs., $4^{\circ}$.

57 Coloquio que tuvieron un Poeta, un Soldado, un Sordo y un Ciego en las gradas de San Felipe, $4^{\circ}$.

58 Embidioso un soldado Vizcayno de Juan Soldado, le da mas por extenso la enhorabuena de la eleccion para esposa a la meritisima Doña Maria Luisa Gabriela Emanuel, pintandola en terminos militares en su lengua vascongada, s.1., [1700], 4 hs., $4^{\circ}$.

59 Coloquio alegórico, En Sevilla, por Francisco de Leefdael, en la Vallestilla, este año de 1703,4 hs., $4^{\circ}$.

60 Coloquio que tuvieron desde sus Xaulas Montesinos, Gayferos y Beltenebros, locos en el Hospital General de esta Corte, [s.l., s.i., s.a.], 4 hs., $4^{\circ}$.

${ }_{61}$ Perico y Marica, buelven a sus antiguos Coloquios, censurando Malcontentos, con el grazejo que verá el curioso en este romance, [s.l., s.i., s.a.], 2 hs., $20 \mathrm{cms}$

62 Podría tratarse de las Coplas para ciegos, $4^{\circ}$ o del Romance de los ciegos en Madrid a nuestro Rey y Señor Don Phelipe Quinto (que Dios guarde muchos años), [s.1., s.i., s.a.], 2 hs., $4^{\circ}$.

${ }_{63}$ El Buen Cazador que por la posta del discurso de Don Juan de Sandobal envio el invictissimo señor Luis Decimoquarto, Rey de Francia, a nuestro Catholico Monarca Phelipe Quinto, s.1., [hacia 1706], 15 pp., $4^{\circ}$.

${ }_{64}$ Un niño loco y leal vassallo de Su Magestad le remite desde el Hospital de Zaragoza este coloquio de la Verdad, al Gran Monarca del Mundo y su Rey, el Señor Rey Don Felipe Quinto (que Dios guarde) dándole la enhorabuena de su reynado y llegada a la Corte, Impresso en Zaragoza, Año de 1701, 8 hs., $8^{\circ}$.

${ }^{65}$ Perico y Aneta, archiducal matraca lusitana, [Sevilla, Francisco de Leefdael, s.a.], 2 hs., $4^{\circ}$.

${ }^{66}$ Aplausos christianos de nuestro gran monarca Rey y señor D. Felipe $V$, en la religiosa... accion que executó el sábado cinco de marzo acompañando a pie a un sacerdote que volvia con el viatico..., Madrid, 1701, 12 págs, $4^{\circ}$.

${ }^{67}$ Alma del Manifiesto ó Respuesta del Serenissimo Elector Duque de Baviera, á las repetidas Letras Avocatorias Cesareas y á la declaracion de Guerra confirmada con la actual invacion de sus Estados, y hostilidad en ellos de sus Enemigos, [al fin: Munich, s.i., s.a.=1703], 8 págs, $4^{\circ}$. 
Academia a que dió assunto la Religiosa accion que executó el Rey ${ }^{68}$

Cara de S.M. Christianissimo al Rey Catolico ${ }^{69}$

Memoria del Embaxador de Francia ${ }^{70}$

Breve del Papa Clemente XI. al Rey Nuestro Senor ${ }^{71}$

Carta de Monsieur de Torsi a los Estados de Olanda ${ }^{72}$

\section{GEOGRAFÍA Y VIAJES}

132. Introduzione alla Storia Naturale e alla Geografia Fisica di Spagna, impresa por Bodoni, 2 vol. Parma 1783

Introduzione alla Storia naturale e alla Geografia fisica di Spagna di Guglielmo Bowles pubblicata e commentata dal Cavaliere D. Giuseppe Niccola d'Azara..., Parma, dalla Stamperia Reale, 1783, 2 vols., $8^{\circ}$.

133. Gumilla Histoire de l'Orenoqüe, [3]vol. Avignon 1758

Gumilla, José, Histoire naturelle, civile et geographique de L'Orenoque et des principales rivières que s'y jettent. Par le P. ..., Avignon, Jean Mossy, 1758, 3 vols., $12^{\circ}$.

134. Diccionario Geografico Universal, 3 vol. Madrid $17834^{\circ}$.

LASERNA, Juan de, Diccionario geographico, o Descripcion de todos los Reynos, Provincias, Islas, Patriarchados, Obispados, Ducados..., Escrito en ingles, y traducido del frances al castellano por... Quarta edicion... aumentada por Antonio de Capmany y Montpalau, Madrid, Miguel Escribano, 1783, 3 vols., $4^{\circ}$.

135. Voyage de la Condamine dans l'Interieure de l'Amerique Meridionale, Maestr. 1778

LA Condamine, Charles-Marie de, Relation abrégée d'un voyage fait dans l'interieur de l'Amérique méridionale... par M. de La Condamine... Nouvelle édition, augmentée de l'Émente populaire de Cuenca au Pérou et d'une Lettre de $M$. Godin Des Odonais contenant la relation $d u$ voyage de $M^{m e}$ Godin, son épouse..., Maestricht, J. E. Dufour et P. Roux, 1778, $8^{\circ}$.

68 Academia, a que dio assumpto la religiosa y catholica Accion, que el Rey nuestro Señor (Dios le guarde) executó el dia 20 de Henero de este Año de 1683. Celebróse el dia 3 de Febrero en casa de Don Pedro de Arce. Fue presidente Don Andrés Sanchez de Villamayor, Madrid, 1683, 48 hs., $4^{\circ}$.

69 Copia de Carta... al Rey Católico en Madrid 25 Enero 1702..., [Madrid, 1702], 12 pp., $4^{\circ}$.

${ }_{70}$ Memoria del embaxador de Francia Monsieur Briod, Barcelona, Figueró, 1700, 8 pp., $4^{\circ}$.

${ }_{71}$ Copia del breve que... escrivio al Rey nuestro Señor Don Felipe Quinto (que Dios guarde) en respuesta de su Real Carta de enhorabuena sobre su ascenso a la Tiara, En Sevilla, por Francisco Garay impressor de libros, en la calle de Vizcaynos, 1701, 2 hs., $4^{\circ}$.

72 Marqués de Torcy, Jean-Baptiste Colbert, Copia de Carta traducida en Español, que de orden del Rey Christianissimo escrivio Monsieur de Torsi a los Estados de Olanda, [Madrid, Antonio Bizarrón], s.a., 2 hs., $8^{\circ}$. 
136. Marmol Descripcion de Africa, primera edición, Granada 1573 fol.

Mármol Carvajal, Luis del, Primera parte de la Descripcion general de Affrica, Granada, en casa de Rene Rabut. Vendense en casa de Juan Diaz, 1573, fol.

137. Relaciones di Pedro Texeira, Antwerp 1610

TEIXEIRA, Pedro, Relaciones de Pedro Teixeira d'el origen descendencia y succession de los Reyes de Persia, y de Harmuz, y de un viage hecho por el mismo autor dende la India Oriental hasta Italia por tierra, Amberes, En casa de Hieronymo Verdussen, $1610,8^{\circ}$.

138. C. Ptolomaei Geographia, exquisitamente encuadernada en tafilete rojo, cantos dorados, véase De Bure, $n^{\circ}$ 4197, Lyons 1541 fol.

Se trata de la famosa edición de Servet.

Tolomeo, Claudio, Cl. Ptolomaei Alexandrini, Geographicae enarrationes libri octo, ex Bilibaldi Pirckeymheri tralatione, sed a Michaele Villanovano (Serveto) secundo recogniti, \& locis innumeris denuo castigati..., Lugduni, apud Hugonem à Porta, anno 1541 , fol. ${ }^{73}$

139. Ulloa Relacion Historica del Viage a la America Meridional, hecho de orden de S.M. con estampas, 5 vol. Madrid $17484^{\circ}$.

UlloA, Antonio de, Relacion historica del viage a la America meridional, Madrid, [tomos 1-4] por Antonio Marin, [tomo 5] por Juan de Zuñiga, 1748, 5 vols., $4^{\circ}$.

140. Voyage de Ulloa, con estampas 2 vol. Lond. 1772

UlloA, Antonio de, A Voyage to South-America... undertaken... by G. Juan and A. de Ulloa... Translated from the original Spanish... to which are added by Mr. John Adams... Occasional Notes and Observations; an Account of some parts of the Brazils... and a Map of South America corrected, London, Lockyer Davis, 1772,2 vols., $8^{\circ}$.

\section{CIENCIAS}

141. Acosta de las Drogas, con estampas, muy raro, Burgos $15784^{\circ}$.

Acosta, Cristóbal, Tractado delas drogas, y medicinas de las Indias Orientales, En Burgos, por Martin de Victoria impressor de su Magestad, 1578, $4^{\circ}$.

73 Esta obra aparece descrita en el artículo 4198 de la obra de De Bure, no en el 4197. Al final de cada una de sus dos partes lleva el colofón «Excudebat Gaspar Trechsel, Viennae, MDXLI».

Comenta De Bure: «On connoit assez dans la République des Lettres la célebre édition de la Geographie de Ptolémée que nous indiquons, si recherchée des Curieux par rapport aux Notes du fameux Michel Servet, dont elle est accompagnée. On la réimprime de nouveau en 1541 à Vienne en Dauphiné, sous les auspices de Pierre Palmier, Archevêque de cette ville, à qui elle fut dédiée. Les deux éditions [1535 y 1541] sont très rares, \& principalement la derniere, qui l'est beaucoup plus que la précédente.» (GuillaumeFrançois DE BURE, Bibliographie instructive ou Traité de la connoissance des livres rares et singuliers. Histoire. Tome premier, Paris, Chez Guillaume-François De Bure le Jeune, 1768, p. 44). 
IX. DERECHO

142. Las Siete Partidas de $\mathrm{D}^{\mathrm{n}}$ Alonso el $9^{\circ}$ glozadas, por el Licenciado Gregorio Lopez, 7 tom. Encuadernado en cuatro vols., Madrid 1789 fol.

Alfonso X, Las Siete Partidas..., Madrid, Benito Cano, 1789, 4 vols., fol.

143. Index Librorum Prohibitorum Madrid 1612 fol.

Index librorum prohibitorum et expurgatorum... Bernardi de Sandoval et Roxas.. Auctoritate et iussu editus. De Consilio Supremi Senatus Stae. Generalis Inquisitionis Hispaniarum, Madriti, Apud Ludovicum Sanchez Typographum Regium, 1612 , fol.

144. Ordenanzas de S.M. para el Exercito, 2 vol. Madrid 1768

Ordenanzas de S.M. para el regimen, disciplina, subordinacion, y servicio de sus exercitos, Madrid, En la Oficina de Pedro Marin impressor de la secretaria del Despacho Universal de Guerra, 1768, 2 vols., $8^{\circ}$. 